\title{
Sequential organization of speech acts in general practice consultation revisited
}

\author{
Miroslav Cerny
}

\section{DOI: 10.18355/XL.2017.10.03.02}

\begin{abstract}
The paper offers partial results of a long-term project aimed at the inquiry into the field of medical interviewing. The main goal of the project is to search for communicative strategies of doctors and patients that can convey empathy and trust. Via an interdisciplinary analysis, based on the data excerpted from the most recent edition of the British National Corpus (2007), the author attempts to bring quantitative and qualitative evidence that doctor-patient communication has undergone significant modifications, resulting in social redefinition of the asymmetrical roles of the main protagonists. The present paper draws attention to those communicative practices of doctors and patients that are related to the sequential organization of speech acts in general practice consultation.
\end{abstract}

Key words: Medical interviewing, sequential organization, speech acts, empathy, British National Corpus

\section{Introduction}

The present treatise reports on an interdisciplinary investigation within the field of medical interviewing, with the aim of discussing communicative practices of doctors and patients that are related to the process of the sequential organization of speech acts. With respect to the key goal of my long-term research, that being a search for discourse strategies of doctors and patients that are capable of conveying empathy ${ }^{1}$ and trust, it focuses on a selected number of strategies, most of which can be characterized as patient-centred and/or expressing equality, mutuality, and symmetry of doctor-patient relationship. Having already examined the role played by questions and responses in general practice consultation, let me devote this paper to other speech act types that occur in this genre of institutional interaction.

For the purposes of the analysis I have taken advantage of the spoken component of the British National Corpus (BNC XML, ed. 2007) and its collection of transcribed and annotated medical interviews. I have selected 50 medical interactions, all of them dyads, with the total extent of text amounting to 34,376 words (that equals 5525 turns). In order to be successful in meeting my research aims, I have combined the statistical perspective ${ }^{2}$ of the medical science with the qualitative viewpoints of

\footnotetext{
${ }^{1}$ In general, I understand empathy as an "emotional experience between an observer and a subject in which the observer, based on visual and auditory cues, identifies and transiently experiences the subject's emotional state. To be perceived as empathic, the observer must convey this understanding back to the subject" (Hirsch, 2009).

${ }^{2}$ I use correlation and the F-test. Correlation is a measure of the relation between two or more variables. The correlation coefficients (I employ Pearson) can range from 1.00 to +1.00 . The value of the former one represents a perfect negative correlation, the value of the latter represents a perfect positive correlation. The F-test calculates statistical evidence whether two samples have the same standard deviation with specified confidence level. Samples may be of different sizes. In lay terms, it proves
}

XLinguae Journal, Volume 10 Issue 3, June 2017, ISSN 1337-8384 
conversation and discourse analysis (cf. Wynn, 1995). My findings are compared and contrasted with findings resulting from previous studies referring to the sequential organization and use of speech acts in doctor-patient interaction, conducted in the 1980s, and early 1990s.

Before presenting the actual analysis and its quantitative and qualitative findings, I find it useful to comment on the issue of speech act theory in general. Just as it is quite difficult to provide an unequivocal definition of a question (see Černý, 2010a), we can also encounter problems on the level of the remaining speech acts. Furthermore, opinions differ even as regards the definition of a speech act as such.

\subsection{Speech Act Theory}

Widdowson (1996: 131) defines a speech act as "an act of communication performed by the use of language, either in speech or writing, involving reference, force, and effect". The theory of speech acts, which today can call on a fifty years of research tradition, has evolved a number of terms that are applied in order to indicate particular classes of speech acts. For example, Austin, whose compilation of lectures titled How To Do Things With Words (1962) is acknowledged as the first step towards speech act theory, delimits four categories: expositives, exercitives, commissives, and behabitives. Bach \& Harnish (1984) sub-classify utterances into constatives, directives, commissives, and acknowledgements. Probably the best known and most frequently applied set of terminology is provided by John Searle (1975), who presents the following speech act categories: representatives, directives, commissives, expressives, and declarations.

$\mathrm{Pu}$ (2003: 221-222) summarizes these categories as follows: (i) representatives are utterances which commit speakers to the truth of the expressed statements; these acts include assertions, stating, confessing, admitting, denying, etc.; (ii) directives are utterances which attempt to have listeners to do something; these acts include commands, requesting, forbidding, warning, advising, insisting, suggesting, etc.; (iii) commissives are utterances which commit speakers to some future action; these acts include promises, pledging, vowing, offering, betting, etc.; (iv) expressives are utterances which express speakers' emotional, psychological state regarding a certain matter; these acts include apologies, welcoming, objecting, congratulations, thanking, etc.; (v) declarations are utterances which bring into reality some change of the status of a given entity in the declarative. These acts include appointing, naming, baptizing, excommunicating, sentencing, etc.

According to the theory (see, e.g., Tarnyiková, 2000: 289-296), any speech act has three aspects: a locutionary act (the act of saying something), an illocutionary act (what is done in saying something, the intended meaning), and a perlocutionary act (what is done by saying something, our intention as recognized by the listener/addressee). Whereas the first and the last facet have not been given much attention in scholarly writings, the illocutionary act is widely discussed.

The central issue of this discussion is the distinction between direct and indirect speech acts (Fraser, 1975; Urbanová, 2003). Direct speech acts are those which show correspondence between a particular syntactic form (declarative, interrogative, imperative) and communicative function or, to apply Searle's terminology, illocutionary force. Indirect speech acts, by contrast, are those in which such correspondence cannot be recognized. With respect to the frequency of occurrence, Crystal (1987: 121) maintains that "some speech acts directly address the

whether two samples differ to such an extent that this differentiation is worth studying. 
listener, but the majority of acts in everyday conversation are indirect". An identical opinion can be also found, for example, in Mey (1993: 143).

Speech act theory, both in general and in its various facets, has been heavily criticised. Proponents of conversation analysis and ethnography of speaking have argued that speech act theorists "do not address a cultural, or contextual, sociological analysis" and that "the basic unit of analysis used is the self-contained action rather than the interaction unit, where context and the role of all participants are important" (Todd, 1983: 161). Wierzbicka goes as far as to say that direct and indirect speech acts should be abandoned as linguistic categories (1991: 88). According to Duranti (1997: 228), "such a theory seems at odds with an anthropological understanding of human action and its interpretation in context". Still, "speech acts remain, along with presuppositions and implicature in particular, one of the central phenomena that any general pragmatic theory must account for" (Levinson, 1983: 226). As Drew \& Heritage (1992) put it: "Perhaps the most vivid point of convergence between language and social organization arises at the level of speech acts. (...) because activities or speech events are built out of particular component actions, speech acts are arguably central to the analysis of all forms of interaction" (1992: 10).

Within the confines of this study, and with respect to what has been just outlined, I view speech acts as actions performed by the use of an utterance to communicate (see Yule, 2000: 134). To align my terms with the terminology used in doctor-patient communication research, I adopt D'Andrade's Speech Act Category System (n.d.), with minor modifications adapted by Todd (1983). Consequently, the category system exploited for the present data consists of seven classes: (i) questions, (ii) answers (iii) statements, (iv) reactives, (v) directives, (vi) commissives, (vii) and expressives. Since questions and answers have been subjects of previous analysis of mine (Černý, 2010a, b), only the remaining five speech act types (i.e. statements, reactives, directives, commissives, and expressives) will be investigated hereafter.

One class from the selected speech act category system definitely deserves specification - reactive. In D'Andrade's original scheme, reactives form a class which includes any response given throughout the interaction: answer, feedback, etc. In Todd's modification, adopted in the present study, reactives form a separate class. While answers are speech acts that provide responses to questions, reactives (right, okay, hmm, aha, etc.) acknowledge the answers given by either dialogue participant (Example 1). ${ }^{3}$

(Ex 1) D:

Your back been giving you trouble again?

(question)

P: $\quad$ Oh terrible.

(answer)

D: Right.

(reactive)

(BNC/H56/19-21)

At this point, I would like to offer a selective summary of results from previous studies concerning the use of speech acts in doctor-patient interaction (Chart 1).

Chart 1:

Findings resulting from previous studies on the use of speech acts in $\mathbf{d}-\mathbf{p}$ interaction

\section{Study Research results}

${ }^{3}$ It is for this reason that reactives should also be distinguished from backchannels or other discourse markers. Though they may take a similar form, their function differs.

XLinguae Journal, Volume 10 Issue 3, June 2017, ISSN 1337-8384 
Wallen et al. (1979): Only $1 \%$ to $5 \%$ of the total time of the medical interview is used by doctors to inform patients.

Todd (1983): Doctors made twice as many statements as patients, and made all the directives.

Todd (1983): Reactives were used by doctors to maintain control of the floor.

Todd (1983): Doctors uttered multiple speech acts per turn, while patients uttered one or two speech acts per turn.

Fisher (1983): Information is provided in ways that function as presentational and persuasional strategies.

Mishler (1984): The three turn 'question-answer-reactive' unit is the most frequent speech act sequence.

Fisher \& Groce (1990): Patients have few opportunities to evaluate the diagnosis or treatment and/or to correct the record.

Roter \& Hall (1992): Doctors speak more than patients; the ratio is $60 \%: 40 \%$.

Coulthard \& Brazil (1992): The three turn unit seems to be a consequence of the asymmetry between participants.

Peräkylä (1995): Doctors resort to explanations when they are not sure about the diagnosis.

\section{Statistical Distributions}

The distributional analysis of speech acts (except for questions and answers) has resulted in the following findings (Table $1 \& 2$ ). Out of 50 medical consultations, comprising 5525 turns (34,376 words), it is possible to distinguish 1184 utterances that could be classified either as statements, directives, reactives, expressives, or commissives. $766(65 \%)$ acts are carried out by doctors, $418(35 \%)$ by patients. 409 $(35 \%)$ acts are used during the info-gathering phase, $170(14 \%)$ during the diagnosis, and $605(51 \%)$ during the treatment section. $782(66 \%)$ acts are statements, $142(12 \%)$ directives, $81(7 \%)$ reactives, $162(14 \%)$ expressives, and $17(1 \%)$ of the excerpted utterances belong among commissives. 
Table 1: Absolute frequency of speech acts in $d-p$ interaction

\begin{tabular}{|c|c|c|c|c|c|c|}
\hline \multirow[b]{2}{*}{ Abs. } & \multicolumn{2}{|c|}{ Participant } & \multicolumn{3}{|l|}{ Phase } & \multirow[b]{2}{*}{ Total } \\
\hline & Doctor & Patient & Info-gather & Diagnosis & Treatment & \\
\hline State & 463 & 319 & 239 & 160 & 383 & 782 \\
\hline Direct & 133 & 9 & 68 & 3 & 71 & 142 \\
\hline React & 79 & 2 & 50 & 4 & 27 & 81 \\
\hline Express & 76 & 86 & 52 & 3 & 107 & 162 \\
\hline Commis & 15 & 2 & 0 & 0 & 17 & 17 \\
\hline Total & 766 & 418 & 409 & 170 & 605 & 1184 \\
\hline
\end{tabular}

Table 2: Relative frequency of speech acts in $d-p$ interaction

\begin{tabular}{|l|l|l|l|l|l|l|}
\hline \multirow{5}{*}{$\%$} & \multicolumn{7}{|l|}{ Participant } & Doctor & Patient & Info-gather & Diagnosis & Treatment & Total \\
\hline State & 60 & 76 & 58 & 94 & 63 & $\mathbf{6 6}$ \\
\hline Direct & 17 & 2 & 17 & 2 & 12 & $\mathbf{1 2}$ \\
\hline React & 11 & 1 & 12 & 2 & 4 & $\mathbf{7}$ \\
\hline Express & 10 & 20 & 13 & 2 & 18 & $\mathbf{1 4}$ \\
\hline Commis & 2 & 1 & 0 & 0 & 3 & $\mathbf{1}$ \\
\hline Total & $\mathbf{6 5}$ & $\mathbf{3 5}$ & $\mathbf{3 5}$ & $\mathbf{1 4}$ & $\mathbf{5 1}$ & $\mathbf{1 0 0}$ \\
\hline
\end{tabular}

In comparison to Chart 1, which illustrates findings resulting from studies on the use of speech acts in doctor-patient interaction arrived at in the 1980s and early 1990s, the statistical data presented in Tables $1 \& 2$ show both similarities and differences. As far as the former situation is concerned, it is evident from the distribution of speech acts $(65 \%$ vs. $35 \%)$ that doctors speak more than patients (cf. Roter \& Hall, 1992). As far as the differences are concerned, my findings can confirm neither Todd's (1983) conclusions that directives are used solely by doctors, nor Wallen et al.'s (1979) view that only $1 \%$ to $5 \%$ of the total time of the medical interview is used to inform patients.

The basic statistical analysis demonstrates that both doctors and patients tend to employ all the selected speech act categories (Examples 2: statements, 3: directives, 4: reactives, 5: expressives, 6: commissives). Nevertheless, it is clear that certain utterance types are far more frequent either on the part of the doctor (e.g. directives, reactives), or on the part of the patient (expressives). It can also be seen in Tables $1 \& 2$ that the most numerous group of speech acts is the category of statements $(782 ; 66 \%)$, whilst the least numerous category are commissives $(17 ; 1 \%)$. Importantly, commissives occur exclusively during the treatment section, regardless of whether they are doctor- or patient-initiated.

(Ex 2) D: $\quad$ There's nothing wrong with those. They're perfect. (BNC/G5X/11)

(Ex 3) D: $\quad$ Now open wide for me, that's fine. Say ah.

P: $\quad A h .(\mathrm{BNC} / \mathrm{GY} 6 / 19-20)$

(Ex 4) P: $\quad(($ cough $))$

D: Do you smoke? Do you smoke?

XLinguae Journal, Volume 10 Issue 3, June 2017, ISSN 1337-8384 

P: $\quad$ No. (cough)
D: Right, okay and nothing coming up? (BNC/GYC/9-12)

(Ex 5) D: $\quad$ See if I do that? [And

P: $\quad$ Ah! $($ ouch $)](\mathrm{BNC} / \mathrm{G} 45 / 70-71)$

(Ex 6) D: So we'll ask her to run through and see what's what. Okay? Follow me. (BNC/G5W/127-127)

When we supplement this rather rough quantification with the calculation of the F-test (see Appendix) and the Pearson correlation coefficient, further conclusions can be drawn. In particular, it can be pointed out that there is no notable correspondence between the category of dialogue participants and the category of dialogue phases $(r=-0.1207)$. By contrast, there is significant distinction between particular speech act types with regard to participants, which suggests that this distinction is worth examining. Besides, we have to take into consideration the statistical fact that the category of commissives differs in its location within the interview from all the other speech act types.

Finding an explanation for the F-test results is simple. The dissimilarity of doctors' and patients' social roles in the medical encounter commit them (to use a verb which refers to one of the speech act types) to behave in a specific way. Whereas doctors are supposed to conduct a verbal and/or physical examination, and then propose an adequate treatment, patients are expected to assist the doctors in the revelation of a diagnosis and, subsequently, follow their advice. That is why there is, for instance, a strong prevalence of doctors' directives, on the one hand, and patients' expressives, on the other. As regards the use of commissives in the final part of the interview, it is understandable that first the diagnosis has to be found, then the treatment procedure presented (by the doctor), and only afterwards can a promise to comply with it or to help with it be given (by the patient or the doctor). This unequal distribution of speech acts is one of the prevailing asymmetrical features of the doctor-patient relationship.

Of course, when evaluating the relationship between patients and healthcare workers on the scale ranging from symmetry to asymmetry, it is essential to take into consideration not only the number of speech acts initiated by the interlocutors, but also the way in which these speech acts are organized within the discourse. It is generally agreed that asymmetrical relationships between doctors and patients are most clearly indicated by the structural unit of $\mathrm{d}-\mathrm{p}$ interaction. "It consists of a sequential set of three utterances: Physician Question - Patient Response - Physician Assessment/Next Question" (Mishler, 1984: 61). The doctor initiates the interview usually with a yes/no question. Then, the patient responds to the doctor's request for information. After that, the doctor acknowledges the response given by the patient, and thus closes the first cycle. Frequently a short pause occurs, and a new speech cycle is opened with another doctor-initiated question (Example 7).

$\begin{array}{llll}\text { (Ex 7) } & \text { D: } & \text { Did they make any difference at all? } & \text { (question) } \\ \text { P: } & \text { No. } & \text { (answer) } \\ \text { D: } & \text { Right. Are you actually getting wheezy with this? (reactive/question) } \\ \text { P: } & \text { Yes, very wheezy, yeah. } & \text { (answer) } \\ \text { D: } & \text { Right. (.) Do you find your cough when you run around? (reactive/question) }\end{array}$ (BNC/G5W/9-13)

Unlike the two-part exchange structure found in everyday interactions between equal participants (Sacks, Schegloff \& Jefferson, 1974), the three-part 
structure is specific to institutional talk. Originally, it was proposed by the Birmingham discourse analysts for classroom exchanges (Coulthard, 1977: 45), and only later was it applied to the institutional setting of health care delivery (Coulthard \& Brazil, 1992: 66). Assessed in this manner, Mishler's sequential set corresponds to Coulthard's Initiative - Response - Feedback. In agreement with D'Andrade's Preliminary Speech Act Category System, Todd (1983: 165) views this structure as a sequence consisting of Question - Answer - Reactive. In what follows, in order to harmonize the variety of terminological labels, Todd's terminology will be employed.

Unlike in classroom interaction, where the third part is initiated by a teacher as an evaluation of a student's work, during medical interaction it carries out a slightly different function: the doctor's reactive is performed in order to maintain control over the medical encounter. According to Mishler (1984: 69): "Through this pattern of opening and terminating cycles the physician controls the turn-taking process; he decides when the patient should take her turn. He also controls the content of what is to be discussed by selectively attending and responding to certain parts of the patient's statements and by initiating each new topic." In other words, this discourse strategy enables the doctor to have the process of the interaction fully in his hands (see Example 8). The patient, by contrast, is designated "a passive and uncritical role in the consultative relationship, his main function being to endure and to wait" (Jewson, 1976: 235).

(Ex 8) D: $\quad$ What else can I do for you?

P: $\quad$ I just need a repeat prescription for Dianette please.

D: Dianette. Yeah. Are you okay?

P: $\quad$ Yeah fine. (BNC/G5Y/25-28)

Unexpected though it may seem, not only doctors but also patients do initiate reactives (Example 9). As Todd contends, "the patient's reactives, however, differ from those of the doctor in that they occur in single speech act turns. The patient does not usually, in her turn, utter a reactive and continue. Rather, she utters the reactive as both the initiation and the end of her turn and in response to the doctor's utterance" (1983: 166). Patients' reactives usually occur at the end of the consultation.

(Ex 9) D: You've had a smear in nineteen ninety one. Paperwork, there's the paperwork. Get that up to date.

P: $\quad$ Er possibly not oh I might be.

D: $\quad$ Yes, it's okay till December so we [don't need to

P: $\quad$ Oh right.]

D: do anything with that (unclear). It'll have to be back dated after Christmas. No problems. Right, blood pressures what I need to check please. Going away next week.

P: You are? Where you going?

D: Oh south Wales.

P: $\quad M m$.

D: $\quad$ The trouble is there's a hundred and one things to do before we

go. (BNC/G5Y/33-41)

As numbers are just numbers, I find it rewarding to look in more detail for the meaning hidden behind them. A qualitative interpretation of the numerical data will be offered in the following sections. The focus will be especially on those aspects of the speech act design that are in some way related to the changing nature of doctor-

XLinguae Journal, Volume 10 Issue 3, June 2017, ISSN 1337-8384 
patient relationship. In particular, attention will be devoted to the communicative strategies of doctors and patients capable of conveying an atmosphere of empathy and trust.

\subsection{Doctor-Initiated Speech Acts}

In spite of what I have just said, let me open the qualitative portion of this study with some more statistics. This time the data concentrate exclusively on doctors and offer only relative numbers. The largest portion of doctor-initiated speech acts consists of statements $(60 \%)$. Much smaller portions of the 'cake' go to directives $(17 \%)$, reactives $(11 \%)$, expressives $(10 \%)$, and commissives $(2 \%)$. Most speech acts initiated by doctors occur during the treatment section $(55 \%)$, then during the information-gathering phase (30\%), and the lowest percentage during the section of diagnosis $(15 \%)$.

My data show that together with questions (see Černý, 2010a), statements are the most frequent doctor-initiated speech act types performed in the medical interview. Whereas doctor-initiated questions occur predominantly in the informationgathering phase, doctor-initiated statements predominate towards the end of the consultation. The main function of statements employed by doctors is obviously that of informing patients. Viewed in the broadest sense of the word, during the phase of diagnosis doctors inform patients about the medical problems (Example 10), while during the treatment phase they transmit information regarding the treatment (Example 11).

(Ex 10) D: You could be starting to be having trouble with your thyroid gland. $^{4}$ (BNC/G4B/47-47)

(Ex 11) D: Just there, you can feel that, feel that, feel it catching. But that's softer than it was before. So that's good.(.) Now, what we'll need to get you doing is some exercise to strengthen up the muscle across there. And pull that scar (.) tight together Jim. (.) What, what I want you to do is, just with you sitting just now, just lift your leg like that, just hold it with your two hands. And just (.) do that. About twenty times a day. (.) Now your knee'll be sore when you start doing it, because you, this muscle has to get strengthened up again. (.) And let that scar get joined up. But as you keep doing that, everyday, it'll get less and less and less painful. And after about a week, there'll be no pain in it, and you'll be (.) doing it no bother at all. And that muscle'll grow over the top of that scar, and it'll get rid of all that for you Jim.

(BNC/G46/23-23)

According to Fisher (1983), there are two main discourse strategies of information giving: (i) presentational and (ii) persuasional strategies. Both are described as 'negotiating mechanisms', which provide information and specify how the info should be understood. The presentational strategy functions as a 'soft sell'. "For instance, a practitioner would say, 'We usually treat this by freezing.' This presentation provides the patient with information about the treatment option while suggesting that it is the usual or normal way to treat her condition" (Fisher 1983: 143). The persuasional strategy, on the contrary, functions as a 'harder sell'. A practitioner "might say, 'What you should do if you don't want any more children is

\footnotetext{
4 "Thyroid gland=endocrine gland in the neck below the larynx" (Dictionary of Medicine, 1996: 359).
} 
have a hysterectomy. No more uterus, no more cancer, no more babies, no more birth control and no more periods." It "provides the patient with information about what treatment she should have while specifying why she should have it" (Fisher 1983: 143).

In terms of negative politeness, it seems to me that the presentational strategy is less imposing, and hence more polite than the persuasional strategy. In terms of asymmetry, the 'soft sell', unlike the 'harder sell', "places the patient in a position where they could, if they wished, question not only the treatment, but the thinking behind it. Therefore, this strategy is significant in balancing the asymmetry between doctors and patients" (Humphreys, 2002: 34). In terms of empathy, it is the presentational strategy that is more empathetic. In connection with the material under present investigation, it is this discourse strategy which is the more frequent (Example 12), though it often combines with elements of the persuasional strategy as well (Example 13).

(Ex 12) D: $\quad$ Yeah, well we could do the same with both of those. They're both, they're both, neither of them are actually warts, okay? They're both rather fleshy skin tanks.

P: $\quad$ Skin tanks.

D: $\quad$ There's two ways of doing this, you can either put some local anaesthetic in and actually burn them off, but that often leaves a bit of a scar. Or you can actually try freezing them to kill them and they just drop off on their own. And [that's

P: $\quad$ Mm.]

D: probably the neater mes method of the two. And certainly the easiest for you. Erm I'd probably give it a go on freezing first, the only thing about the freezing is sometimes it doesn't work first time. But that'd be the tidiest thing for you. And [we

P: $\quad M m$.

D: $\quad$ can get that set up. Now I'm actually, there isn't another session now until the week after next, cos I'm actually away next week.

P: $\quad M m$.

D: $\quad$ Er er but then we'll have more sessions booked in, we can just slot you in to one of those I should think.

P: $\quad$ Yeah. (BNC/GY5/7-16)

(Ex 13) D: Right, what we need to do is to hit it fairly hard and try to get it damped down as quickly as we possibly

can. Now don't get rid of the Betnovate, have you still got some

left?

P: $\quad M m$.

D: $\quad$ Okay. Because as soon as it starts to die down you could probably go back on to Betnovate to keep it maintained. And you may actually have to use Betnovate on a preventative basis every now and again. Even if there's not a deal there, as soon as it starts it's slightly flaky straight in. But what I'm gonna do is give you erm Dermavate Dermavate is actually more potent than Betnovate in the ointment form again to get the rapid penetration. And once again, like Betnovate it's used twice a day. And in a similar fashion you should use the Dipabase to keep the skin as soft and moist as you can

P: $\quad M m$.

XLinguae Journal, Volume 10 Issue 3, June 2017, ISSN 1337-8384 
D: $\quad$ rather than letting it get dried out and cracked. Dermavate is, as I say, it's more potent, it's probably not so suitable for keeping going with, but for jumping on top of things in a hurry, it's fine. And I think that's what we ought to use. Sometimes you actually need to use it under something, but it's difficult to use under things and part of the hand. (laugh) (BNC/GYE/29-33)

Obviously, information-giving frequently uses interpreting and clarifying techniques. My data includes repeatedly occurring sequences of doctor-patient exchanges in which the patient poses a question, the doctor provides an answer, and then the doctor elaborates the answer by furnishing a more detailed interpretation of the information. For instance, in the following example (Example 14), the patient whose medical problem is eczema - plans to go to Spain on holiday and therefore she asks the doctor whether there can be any problems with swimming. The doctor answers and adds an explanatory remark. This verbal behaviour of the particular doctor can be classified as patient-centred.

(Ex 14) P: $\quad$ What about swimming and things? I mean (unclear)

D: $\quad$ Yeah you're okay, you can go swimming, it shouldn't do you any harm. I mean in things like swimming baths are chlorinated so they've got a low bug count anyway, so, so you'll be at low risk of getting anything there. (BNC/GYE/78-79)

In Mishler's (1984) point of view, patient-centredness is enhanced when the doctor's explanation and interpretation of the medical agenda is provided via more accessible terminology. Interestingly, in the interviews analyzed here, doctors not only tend to switch from their medical jargon to expressions that are closer to language of laymen (Example 15), but sometimes even make fun of the use of medical terminology, and thus of themselves (Example 16).

(Ex 15) D: Okay. (22.0) Alright. Now, I've given you some cream to put on (unclear) as well, Anne.

P: Right.

D: $\quad$ Now, put that on three times a day and you put the tablets, you

take

P: $\quad$ What the tablets for?

D: It's an antibiotic stuff to clean it from the inside.

P: $\quad$ Ah right. (BNC/H51/22-27)

(Ex 16) D: Restless legs it's called.

P: Ooh.

D: Restless legs, and it sums it up, because ((ha-ha)) they do get restless. It's got a posh name, I can't remember what it's called now, but it has got a posh name too.

P: I know they all have but I mean I'd rather have the ordinary

names [and then

D: $\quad$ Yeah.] Well so would I cos I [remember them I can't

P: And then I know.]

D: I can't remember the posh names usually.

P: $\quad$ The same with flowers and all them plants and that. I'd much rather have a plain name I know what they're talking about. (BNC/G5R/194-201) 
Clearly, doctors are often attentive to patients' needs and worries. They help patients better understand their health problem and the benefits of the proposed treatment. Doctors share with patients information regarding medical facts and the management of their condition. In more detail, to apply Cordella's classification of doctors' voices (2004), they assist with conveying information about (i) available test results, (ii) proposed tests, and (iii) the functioning of the human body. During this assistance, doctors play the role of the educator and, in doing so, they "promote the principles of preventative medicine and encourage compliance" (Cordella, 2004: 87). This fact corresponds to Brody's (1980) requirements that doctors' verbal contributions should include the education of the patient about the nature of her problem, discussing the pros and cons of the alternative evaluation and treatment approaches, and the explanation of health recommendations. ${ }^{5}$

While in the role of the educator, doctors still concentrate rather on the medical side of the encounter with the patient. The following discourse strategies enable them to support what Cordella (2004) refers to as the fellow human voice, i.e. the ability to encourage patients to share their life stories and to exhibit empathy. This can be done not only via a number of questioning and responding activities (see Černý, 2010a), but also via other speech acts (e.g. statements, expressives).

All of the discourse strategies that I am about to introduce involve a certain degree of interrupting the patient's talk. Importantly, interruptions (and overlaps) are not necessarily associated with claiming control over the interaction, but may also demonstrate support, trust, and cooperation (Goldberg, 1990). The cooperation between the interlocutors in the medical consultation may even take the form of joint production of speech (see, e.g., Falk, 1980; Lerner, 1991; and Schegloff 1984), which is to be understood as the co-production of an utterance by both interlocutors.

According to Ferrara (1992: 219): "Joint productions (...) are a second speaker's attempt to contribute to the syntactic and semantic intent of the first speaker. At times joint productions are explicable as efforts to clarify, to ensure completeness or correctness in terms of information and truth value, and these semantic wishes are performed with syntactically compatible contributions by a second speaker to the first speakers' utterance. The result is one sentence contributed by two interactants." It appears to me that Ferrara's description of joint productions is close to what Tannen (see 1984, 1986) labels as cooperative overlap, or what Goldberg (1990) classifies as neutral or relationally relevant interruptions.

Ferrara (1992) distinguishes four main types of joint production: (i) utterance extension, (ii) predictable utterance completion, (iii) helpful utterance completion, and (iv) invited utterance completion. While the first three can be found in the material under scrutiny, the fourth type - "induced by initial speaker's eliciting the sentence completion from the second speaker by means of a word stretch (namely syllable elongation) followed by a brief pause" (Ferrara, 1992: 221) - has no representative in my sample. In my opinion, this fact is not as surprising as it would be quite strange if the patient prompted the doctor to complete what she is supposed to finish. ${ }^{6}$

Utterance extension is described as "the feasibility that a sentence or sentence analog can be extended by a second speaker beyond the point at which the first speaker considered it complete" (Ferrara, 1992: 217). In the following extract

\footnotetext{
${ }^{5}$ Expectedly, under certain conditions, for example when he is not sure about the diagnosis (Peräkylä, 1995) or when he has to respond to patient discomfort (Cordella, 2004), the doctor resorts to explanations in order to protect his medical authority.

${ }^{6}$ Ferrara's (1992) classification is used in Cordella (2004).
} 
(Example 17), a doctor prescribes a medicament to a patient who suffers from neuralgia. $^{7}$ The patient complains about how expensive it is to pay for one prescription or two. The doctor extends her contribution by empathic assent that three would be even worse. The patient reacts in an affirmative way, thus indicating that she does not see the doctor's comment as an attempt to grasp the floor but rather as gentle way of empathizing with her.

(Ex 17) D: $\quad$ Now this is the latest stuff from the (.) the hospital (.) for killing neuralgia.

$\mathrm{P}: \quad$ Is it?

D: $\quad M m$. (.) Now, no more than three times of these in a day, and you must stay on it for at least a month.

P: Right.

D: $\quad$ A whole month, Agnes.

P: Are you giving me a month's supply?

D: Mmm. Yeah.

P: $\quad$ Cos (unclear), how much, four seventy five now for a prescription, is

D: $\quad$ [Yeah, well

$\mathrm{P}: \quad$ is not?]

$\mathrm{D}: \quad$ (unclear)

P: $\quad[$ It's

D: Aye.]

P: $\quad$ it's not so bad when you get one,

D: (cough)

P: but see when you get two? Or

D: Three.

P: $\quad$ Er it's terrible. $(\mathrm{BNC} / \mathrm{G} 45 / 86-101)$

In predictable utterance completion, the "speakers project their intended utterances well before their point of completion" (Ferrara, 1992: 219). Example 18 illustrates how the doctor can convey empathy by predicting what the patient wants to tell him. It is especially important in cases that are emotionally tense, for example when the interview topic is the death of the patient's close relative. Here, the joint production is made easy by the pause preceding the doctor's contribution, and acknowledged by the patient's agreement form. We can also see that the topic is further developed by both speakers.

(Ex 18) D: $\quad$ That's right. That's just a stress reaction.

P: It's see yeah well, did you know my mother died?

D: No.

P: $\quad$ Yeah. She died on the thirteenth of March. She was only in that

new home fi five weeks.

D: Right.

P: $\quad$ Five weeks she was in it. But don't get me wrong, it wasn't a (.) it

wasn't a (.) er (.) tragedy as such when (unclear) [cos it was the

D: No no. Oh]

P: $\quad$ best thing that could have happened [to

\footnotetext{
7 "Neuralgia=spasm of pain which runs along a nerve; trigeminal neuralgia=pain in the trigeminal nerve, which sends intense pains shooting across the face" (Dictionary of Medicine, 1996: 234).
} 


$\begin{array}{ll}\text { D: } & \text { Yeah.] } \\ \text { P: } & \text { my mother. Because she was }(.) \\ \text { D: } & \text { She was never happy. } \\ \text { P: } & \text { Ah, that was. You know. } \\ \text { D: } & \text { It was a, a release. } \\ \text { P: } & \text { It was a release because she just went down everyday. } \\ \text { D: } & \text { Yeah. Oh aye. } \\ \text { P: } & \text { She went down everyday. (BNC/G45/113-128) }\end{array}$

Helpful utterance completion is defined as "minimal additions offered by a listener who detects some difficulty on the part of a speaker in accessing an item in the mental lexicon" (Ferrara, 1992: 220). There are only a few examples of this type of joint production in the language material that is studied here. In the following extract (see Example 19), the patient comes to the consulting room with a persistent cough and cold. In the course of the medical interview, she tells the doctor about an old remedy she has tested, and suddenly she seems to hesitate how to continue. The doctor offers the 'helpful utterance completion' (...but it still hasn't worked?), which is sequentially confirmed by the patient.

(Ex 19) D: Do have a seat Mrs (anonym) anyway, what can I do for you today?
P: $\quad$ Well it's this damn cough and cold get.
D: $\quad$ Still coughing?
P: I've had it since just before Christmas and it keeps going and coming.
D: $\quad$ Mm. Are you coughing anything up with it?
P: $\quad$ No I can't I, I heave with it but I can't get nowt up.
D: Right.
P: $\quad$ I made myself some medicine, some er honey, glycerin and apple cider vinegar.
D: $\quad M m$.
P: $\quad$ It's an old remedy but I think
D: but it still hasn't worked?
P: $\quad$ No.
D: No.
P: $\quad$ No. $(\mathrm{BNC/GY6/3-16)}$

As there is no video recording at hand, it is of course difficult to decide unambiguously whether the patient really has problems expressing herself correctly (e.g. due to her stress) and the doctor is willing to supply suitable lexical items, or whether the doctor interrupts her speech without the intention of helping to complete the patient's verbal contributions; simply because he wants to accelerate the encounter.

Another discourse strategy which is worth mentioning at this point is in a way related to the joint production of speech. Doctors may support and cooperate with patients not only by extending and completing their utterances, but also by repeating their last word(s) or the whole utterance(s). This repetition is most often referred to as mirroring (see, e.g., Coates, 1996), sometimes as echoing. Whatever the designation is, the strategy can definitely be regarded as an effective communicative device that enables doctors to show special attentiveness to patients' stories. Mirroring "has the effect of accelerating the conversation but does not disrupt the patient's account" 
(Cordella, 2004: 137). When the words are repeated, patients can be sure that they are being understood (Example 20).

\begin{tabular}{|c|c|c|}
\hline$($ Ex 20) & D: & Yeah. \\
\hline & P: & Friday [to see \\
\hline & D: & Right.] \\
\hline & P: & Doctor. \\
\hline & D: & Right. Now have you plenty of the wee tablets or are you finished? \\
\hline & P: & No, I finished 'em. \\
\hline & D: & Finished all that lot. Right, Agnes. \\
\hline & P: & $\begin{array}{l}\text { Finished them on Saturday. Mm that's how I was, I was } \\
\text { saying had been at the hospital, come back and says no, [my, }\end{array}$ \\
\hline & D: & No.] \\
\hline & P: & tablets are finished, I'd better go to the doc. \\
\hline & D: & $\begin{array}{r}\text { No, you'd better. You need to get that, need to keep that down } \\
\text { because if you do go to the hospital, and they did decide }\end{array}$ \\
\hline $\begin{array}{l}\text { to take th } \\
\text { and they }\end{array}$ & & $\begin{array}{l}\text { out, they would they would check your blood pressure } \\
\text { would chase you. There's no way they would touch it at all. So }\end{array}$ \\
\hline & P: & It's no, I don't really know cos the doctor says she didn't know \\
\hline $\begin{array}{l}\text { what } \\
\text { pulled }\end{array}$ & & $\begin{array}{l}\text { it was either. Doctor (anonym) seen it first, she thought I had } \\
\text { a hair and it was kind of septic. }\end{array}$ \\
\hline & D: & Septic aye. \\
\hline & P: & and she gave tablets, \\
\hline & D: & [Aye, that leaves \\
\hline & P: & antibiotics.] \\
\hline & D: & leaves a wee cyst underneath the skin. \\
\hline & P: & Is that what it would \\
\hline & D: & {$[\mathrm{Mhm}$. } \\
\hline & P: & be then?] \\
\hline & D: & Yeah, that's probably what it is. \\
\hline & P: & It it's no really er giving me any \\
\hline & D: & [No. Just, no. \\
\hline & P: & much trouble or anything,] but it was just the fact of it being \\
\hline
\end{tabular}

there.

D: It's there. It's there. (BNC/H5V/49-73)

What psychologists and psychotherapists view as the primary therapeutic technique utilizing words is reflection (Rogers, 1986). It functions as an empathic acknowledgement of the explicit and implicit feelings of a client (Ivey \& Ivey, 2003). "Through a reflection, a counselor or a therapists [or a general practitioner] is able to capture the inner experience of a client and convey this understanding back to the individual from an immediate or extended perspective" (Clark, 2007: 190). As might be expected, this type of discourse strategy requires a much more sophisticated 'art' of communicating than mere mirroring. The feedback given to patients should reflect both the direct ideas presented by the patient as well as the ideas offered indirectly or signalled by hints. The doctor is supposed to listen carefully to what the patient is implying. The shared experience is often not related to the medical condition of the patient (Example 21). In fact, only few instances in my material can be unequivocally classified as reflections.

(Ex 21) P: But it's [so

D: $\quad$ But]

P: $\quad$ much hurt, you know. 


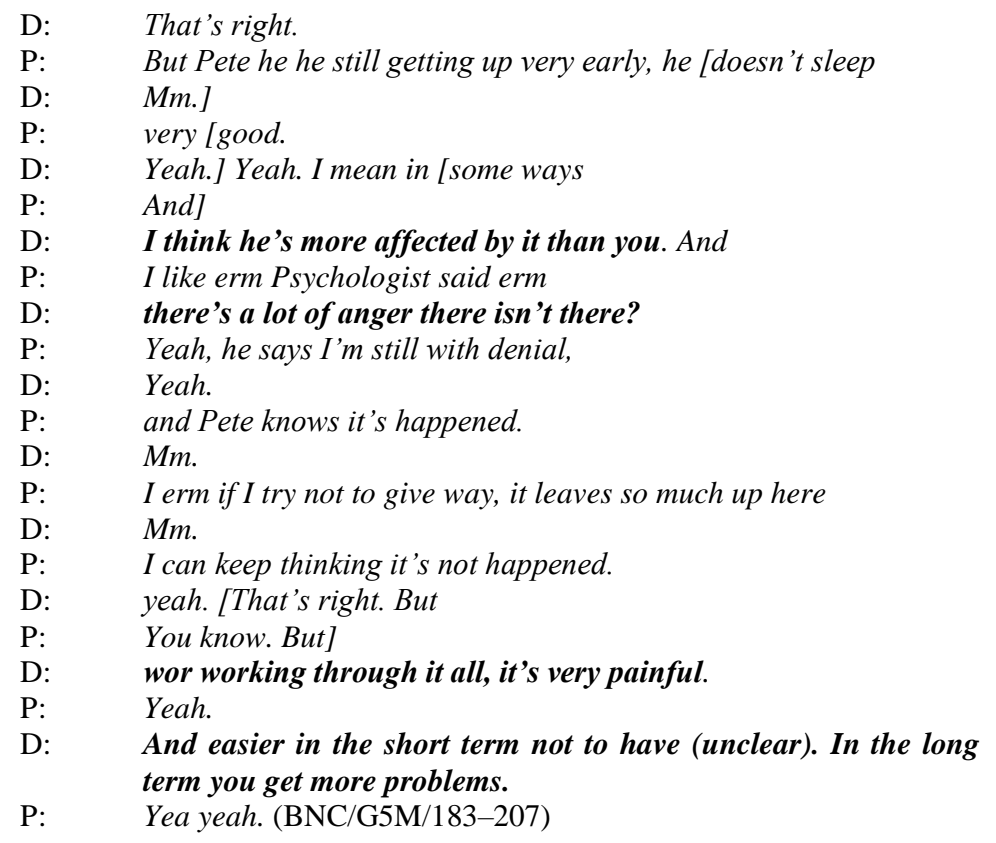

The above example is extracted from a much larger consultation (consisting of 229 turns and 1788 word units) in which the talk between the doctor and the patient is promptly switched from the medical issue to the personal problem of the patient. Interestingly, it is the doctor who initiates this topic change, probably because the patient's family sorrows, resulting in deep stress, are closely related to her medical condition. We do not know much about what the problem concerns. The doctor and the patient refer to some event which is known to both of them, so they do not have to relate to it directly; the patient only gives details regarding the current state of the problem. What we know is that the family of the patient, or some of the family members, are to be taken to court.

Discussing the problem takes up the largest part of the interview; it starts with turn 28 (how are things going on from the other point of view?) and continues until the end of the encounter. During this space-time, the doctor behaves very empathically: he reflects the feelings of his patient (130: there's an awful lot pressure on you from an awful lot of other sources), offers the patient his own time (142: if you want to pop in and have a chat with me in between that's fine), and even discloses his personal experience (176: you know doctors get sued every now and then). However, as I have already noted, this psychotherapeutic approach is very demanding and practitioners usually have no time for such a long revelation of their humane support.

It seems to be evident that all of the doctor's communicative strategies mentioned so far employ, preferentially, speech act types categorized as statements. Nevertheless, there are two more categories of speech acts that deserve our attention because under specific formal and/or contextual conditions they are efficient in transmitting a certain degree of empathy, equality, and patient-centredness: these are (i) expressives and (ii) directives.

The members of the first category (i.e. expressives) enable the doctor to communicate a spontaneous emotional reaction to the patient's verbal contributions. In Cordella's (2004: 135) view this emotional reciprocity "allows the doctor to show

XLinguae Journal, Volume 10 Issue 3, June 2017, ISSN 1337-8384 
affiliation with the patient by removing the constraints imposed by the strictly medical discourse". As is obvious from the following illustrations, most expressives take the form of one-word, only rarely two- or three-word utterances (Examples 22, 23 and 24). In addition, the use of emotional features of discourse frequently results in linguistic shift to a more colloquial register of interaction on the part of the doctor (Example 25).

(Ex 22) D: You're not getting any funny fits from that at all, June?

P: Erno.

D: Nothing? (.) Ah. That's excellent. Excellent. (BNC/H4P/24-26)

(Ex 23) D: $\quad u$ give you some antihistamines, did they make any difference at all?

P: $\quad$ No.

D: $\quad$ Oh dear. (BNC/G5W/9-11)

(Ex 24) D: $\quad$ Did it just come on all of a sudden?

P: $\quad$ I think what happened it started on my legs, here. Right?

D: $\quad$ Oh deary me. (BNC/H5A/13-15)

(Ex 25) D: $\quad$ Let's have another look at this. Oh my. For goodness sake. (haha) There's a wee man with a pick and shovel in (unclear) (BNC/H4U/11-11)

As far as directives are concerned, the situation is more complicated. The employment of this speech act category is usually assessed as a manifestation of the asymmetry and unequal nature of relationship between the interactants. However, there are cases when the imposing character of directives is either mitigated or levelled. The first process can be accomplished when the indirect form of the speech act is exploited (Examples 26 and 27). The second process usually takes place when the contextual circumstances allow the doctor to act in a rather informal, even humorous way. Such circumstances usually appear at the end of the interview (Example 28).

(Ex 26) D: $\quad$ Okay, can you slip your shoe and sock off. (BNC/G5R/26-26)

(Ex 27) D: Do you think you can roll your sleeve up. (BNC/GYC/78-78)

(Ex 28) D: $\quad(h a-h a)$

P: $\quad((h a-h a))$

D: $\quad$ Away and look after yourself. (BNC/G45/140-142)

Though direct forms of this speech act category are more frequent (Example 29 and 30), I cannot say that it would always be more effective if the indirect variants were used. The directness of doctor's talk is able to accelerate the progress of necessary and, unfortunately, often unpleasant sections of the medical consultation, the physical examination in particular (see Example 31). In addition, it can function as a pre-explanation sequence that helps the patient towards an understanding of what her medical problem involves (Example 32). Thus, the use of directives can sometimes be viewed as patient-centred.

(Ex 29) D: Right. Show us your muscles. (BNC/H5V/17-17)

(Ex 30) D: $\quad$ Stick your finger on there. (BNC/G4B/83-83) 
(Ex 31) D: $\quad$ Aye. Your gums are all inflamed as well. Aye. Put your tongue back out for a wee look. That side of your mouth's all infected as well. (BNC/H4V/12-12)

(Ex 32) D: $\quad$ Aye. Just your, let your foot rest on the floor, Anna. Yeah. You can see there's been a wee bit of damage

to that ligament just where it goes down over the top of that bone. (BNC/G4D/112-112)

\subsection{Patient-Initiated Speech Acts}

The largest proportion of patient-initiated speech acts can be classified as statements $(76 \%)$. Another significant proportion can be classified as expressives (20\%). The remaining three types are less numerous: the category of directives comprises just $2 \%$ of the total number, the category of reactives only $1 \%$, and the very same percentage is represented by commissives $(1 \%)$. Most speech acts employed by patients occur during the treatment phase (44\%). About the same proportion of speech acts occurs during the info-gathering phase $(42 \%)$. The lowest proportion of patientinitiated speech acts belongs to the diagnosis (14\%).

It has been proved that patients use the same spectrum of speech act types as doctors do. Naturally, patients use particular speech acts with different intentions and under different circumstances than their doctors. For example, the second most numerous patient-initiated speech act type - expressives - is not employed with the aim of communicating emotional reciprocity, but rather to express that the physical examination hurts (Example 33). Similarly, patient-initiated directives (most frequently in their indirect variant) should not be interpreted as utterances related to the current process of the doctor-patient communication itself; in fact they are polite requests referring to the subsequent treatment and activities that are linked with it (Example 34).

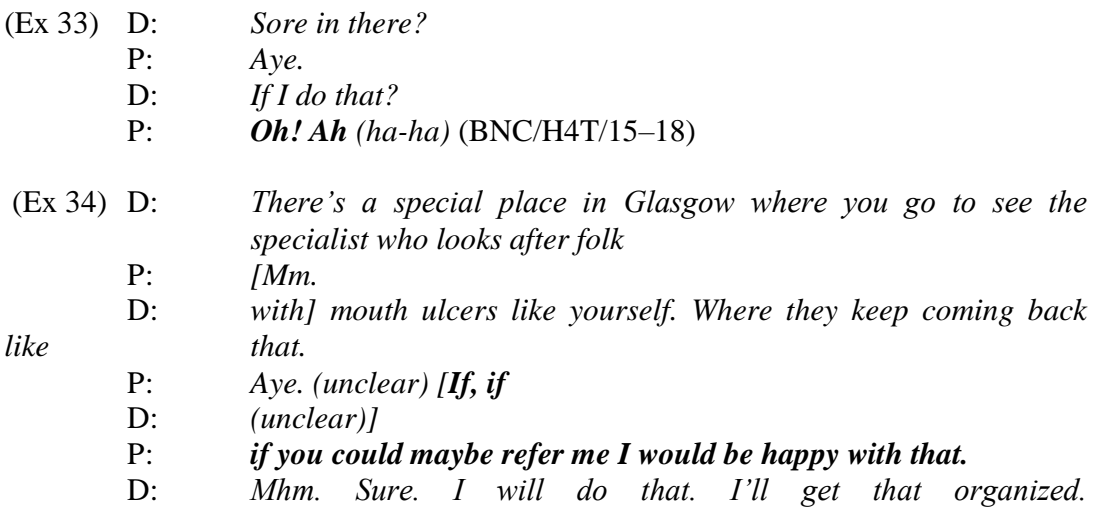
$(\mathrm{BNC} / \mathrm{H} 4 \mathrm{~V} / 2228)$

The most significant discourse strategy that requires the initiation of statements has been named by scholars health-related storytelling. According to Cordella (2004: 153), patients often expand their narrations related to health (i) by describing their emotional state, (ii) by describing their symptoms, (iii) by expressing concern about their health condition, treatment or management, and (iv) by sharing

XLinguae Journal, Volume 10 Issue 3, June 2017, ISSN 1337-8384 
their difficulties in complying with medical recommendations. This is precisely what can be found in my material (Example 35). Importantly, this finding challenges both the argument that only doctors utter multiple speech acts per turn (Todd, 1983) and that patients have few opportunities to evaluate the diagnosis or treatment and/or to correct the record (Fisher \& Groce, 1990).

(Ex 35) P: $\quad$ That's how I feel. I hurt I [really hurt.

D: Mm.]

P: $\quad$ Here all up here, here in my arms I mean I had seven week

D: No.] physiotherapy on his arm, it's no better now [than

P: $\quad$ what it were when I started going.

D: $\quad M m$.

P: It's all, it dead, [it's

D: Mm.]

P: $\quad$ it hurts. I wake up like it, I go to bed like it, I've got it all the time that I'm living with a bloody nightmare,

all the time. And I don't think it's from that hand.

D: $\quad M m$.

P: I don't, don't for a minute think it's from that hand, because you know the tingling, you're are supposed to get tingling all time?

D: $\quad$ You can do, yes.

P: $\quad$ Well I don't.

D: $\quad$ You can do.

P: Idon't.

D: Not necessarily.

P: $\quad$ I it's these bones what hurt here.

D: $\quad M m$.

P: $\quad$ That's the main problem there. Th when I'm, I'm picking doing owt it hurt, really hurt.

D: $\quad M m$.

P: It's like as though I've in mangle. And this is like two day where I just aching, burning. You know I don't know what to do with myself sometimes. I can't sit and watch television, I can't knit I sit and read and I'm tightening up up like this and I like that to sort of

D: $\quad M m$.

P: I'm always doing that, I'm bloody daft when I do it, but it, it sort of releases tension. (BNC/GY6/90-114)

\section{Conclusion}

The present study should be viewed as an important complement to what has been presented in my previous articles on questioning and responding strategies. It offers an investigation into the sequential organization of other speech act types that are used by the main interview participants, and attempts to examine their chief discourse functions. I am fully conscious of the fact that the findings I have delivered are only partial, and that they should be developed further and either confirmed or challenged by much more comprehensive research which would not limit itself to an analysis based on written transcripts and would take advantage of video recordings. I am also aware of the disadvantages of speech act theory, especially as far as the coding procedure is concerned. Nevertheless, the benefits of this approach are, in my opinion, still valid and should not be avoided. 
The distributional analysis of the principal speech act types (statements, reactives, directives, expressives, and commissives) revealed that there is a certain disparity in the amount of talk (i.e. verbosity) effected by the doctor, on the one hand, and the patient, on the other hand, with the larger proportion on the part of the former speaker. The analysis also demonstrated that although both interactants employ all speech act types, certain types are far more frequently used by doctors (directives, reactives) and others by patients (expressives). This unequal distribution of speech acts is due to the dissimilar social roles that doctors and patients play in the medical encounter, and prevails as one of the traditional asymmetrical features of the doctorpatient relationship. The inequality of verbal practices of doctors and patients is further supported by the use of the three-part structural unit of doctor-patient interaction, consisting of the doctor's question, the patient's response, and the doctor's reactive, which enables the doctor to claim his power over the patient and maintain control over the interaction.

At the same time, as the qualitative analysis reveals, it needs to be stressed that doctors often employ speech acts with the intention of expressing attentiveness to patients' needs and fears, to assist the narration of patients' stories, and to show close affiliation with the emotional world of their patients. There exist a number of diverse discourse strategies which are used to accomplish this goal. Statements, for example, are used with the aim of informing patients, to provide an interpretation of the information given by presenting details that concern the diagnosis discovered and the treatment recommended. Doctors try to perform all this in a soft and reflective manner, in joint production with their clients. Also doctor-initiated directives are often organized in such a way that they either strengthen patient-centredness or that their imposing character is somewhat mitigated by the utilization of their indirect variants. Expressives communicate emotional reciprocity and entail shifts to a more colloquial style of interaction.

Regarding patient-initiated speech acts and their contribution towards conveying an atmosphere of trust, there is one strategy whose importance should be stressed: health-related storytelling. The fact that patients are able to talk about their personal perspectives on their medical problems allows the doctor to gather relevant information to reach a responsible diagnosis. Moreover, such behaviour supports the doctor's confidence in his patients. In relation to this, the fact that doctors grant patients time to share their stories indicates that the originally asymmetrical nature of doctor-patient relationship has indeed been modified in favour of the latter. It is also important that my conclusions, based on the English language material, align with some of the findings arrived at by Cordella (2004) using language data from an Spanish-speaking environment. 


\section{Appendix}

Below are results of the F-test, containing calculations relevant for the quantitative section of the present study. The asterisk indicates when the results are of particular significance.

F-test calculation of speech acts with respect to participants and interview phases

\begin{tabular}{|l|l|l|l|l|}
\hline F/ Participant & Direct & React & Express & Commis \\
\hline State & $6 \mathrm{E}-20 *$ & $4 \mathrm{E}-25^{*}$ & 0.7501 & $0.0672^{*}$ \\
\hline Direct & & $0.00002^{*}$ & $9.00 \mathrm{E}-17^{*}$ & $0.0616^{*}$ \\
\hline React & & & $2.00 \mathrm{E}-23^{*}$ & $5.00 \mathrm{E}-06^{*}$ \\
\hline Express & & & & $0.0611^{*}$ \\
\hline
\end{tabular}

\begin{tabular}{|l|l|l|l|}
\hline F/ Phase & Direct & React & Express \\
\hline State & $0.0385^{*}$ & 0.3519 & 0.2564 \\
\hline Direct & & 0.5866 & 0.4501 \\
\hline React & & & 0.9392 \\
\hline
\end{tabular}

\section{Bibliographic references}

AUSTIN, J. L. 1962. How to Do Things with Words. Oxford: Claredon Press. ISBN 9780674411524.

AUSTIN, J. L. 1970. Philosophical Papers. Oxford: Oxford University Press. ISBN 9780192830210.

BACH, K. - HARNISH, R. M. 1984. Linguistic Communication and Speech Acts. Cambridge: The MIT Press. ISBN 9780262520782.

BRODY, D. 1980. The Patient's Role in Clinical Decision Making. In: Annals of Internal Medicine, n. 93, pp. 718-722. ISSN 00034819.

CLARK, A. 2007. Empathy in Counselling and Psychotherapy. New Jersey: Lawrence Erlbaum Associates. ISBN 9780805859508.

COATES, J. 1996. Women Talk. Conversation between Women Friends. Oxford: Blackwell. ISBN 9780631182535.

COLLIN, P. 1996. Dictionary of Medicine. Teddington: Peter Collin Publishing. ISBN 9781579580742.

CORDELLA, M. 2004. The Dynamic Consultation. A Discourse Analytical Study of Doctor-Patient Communication. Philadelphia: John Benjamins. ISBN 9789027253712.

COULTHARD, M. 1977. An Introduction to Discourse Analysis. London: Longman. ISBN 9780582553798.

COULTHARD, M., BRAZIL, D. 1992. Exchange Structure. In: Coulthard, M. (ed.). Advances in Spoken Discourse Analysis. London: Routledge, pp. 50-78. ISBN 9780415066877.

CRYSTAL, D. 1987. The English Encyclopaedia of Language. Cambridge: Cambridge University Press. ISBN 9780521736503.

ČERNÝ, M. 2010a. Questioning and Responding Practices in Medical Interviews Revisited (Part I: Doctors). Ostrava Journal of English Philology, n. 1, pp 67-83. ISSN 18038174. 
ČERNÝ, M. 2010b. Questioning and Responding Practices in Medical Interviews Revisited (Part II: Patients). Ostrava Journal of English Philology, n. 2, pp. 31-42. ISSN 18038174.

D'ANDRADE, R. (n.d.). A Tentative Cultural Classification of Speech Acts. San Diego: University of California, n.d.

DREW, P. - HERITAGE, J. (ed.). 1992. Talk at Work. Interaction in Institutional Settings. Cambridge: Cambridge University Press. ISBN 9780521376334.

DURANTI, A. 1997. Linguistic Anthropology. Cambridge: Cambridge University Press. ISBN 9780521449939.

FERRARA, K. 1992. The Interactive Achievement of a Sentence. Joint Production in Therapeutic Discourse. In: Discourse Processes, n. 15, 1992, pp. 207-228. ISSN 15326950.

FISHER, S. 1983. Doctor Talk/Patient Talk. How Treatment Decisions Are Negotiated in Doctor-Patient Communication. In: Fisher, S. - Todd, A. (eds.). The Social Organization of Doctor-Patient Communication. Washington, D.C.: The Center for Applied Linguistics, pp. 135-158. ISBN 9780155990678.

FISHER, S. - GROCE, S. 1990. Accounting Practices in Medical Interviews. In: Language in Society, n. 19, pp. 225-250. ISSN 00474045.

FRASER, B. 1975. Hedged Performatives. In: Cole, P. - Morgan, J. (eds.). Syntax and Semantics 3. New York: Academic Press, pp. 187-210. ISBN 9780127854236.

GOLDBERG, J. 1990. Interrupting the Discourse on Interruptions. In: Journal of Pragmatics, n. 14, pp. 883-903. ISSN 03782166.

HIRSCH, E. 2009. The Role of Empathy in Medicine. A Medical Student's Perspective.

Available [online]: <http://virtualmentor.ama-assn.org/2007/06/medu1-0706.html> Retrieved 2009-10-18.

HUMPHREYS, J. 2002. The Role of Questions and Answers in Doctor-Patient Interaction.

Available

[online]:

<http://www.ling.lancs.ac.uk/staff/florencia/201/res/diss/humphreys.pdf > Retrieved 2002-03-11.

IVEY, A. E. - IVEY, M. B. 2003. Intentional Interviewing and Counselling. Facilitating Client Development in a Multicultural Society. Pacific Grove: Brooks/Cole. ISBN 9781285065359.

JEWSON, N. 1976. The Disappearance of the Sick-Man from Medical Cosmology, 1770-1870. In: Sociology, n. 10, pp. 225-244. ISSN 00380385.

LERNER, G. 1991. On the Syntax of Sentence-in-Progress. In: Language in Society, n. 20, pp. 441-458. ISSN 00474045.

LEVINSON, S. 1983. Pragmatics. Cambridge: Cambridge University Press. ISBN 9780521294140.

MEY, J. 1993. Pragmatics. An Introduction. Oxford: Blackwell. ISBN 9780631211327.

MISHLER, E. 1984. The Discourse of Medicine. Norwood: Ablex Publishing Corporation. ISBN 9780893912772.

PERÄKYLÄ, A. 1995. AIDS Councelling. Institutional Interaction and Clinical Practice. Cambridge: Cambridge University Press. ISBN 9780521022880.

PU, M.M. 2003. Discourse Analysis. In: Štekauer, P. - Kavka, S. (eds.). Rudiments of English Linguistics II. Prešov: Filozofická fakulta Prešovskej univerzity, pp. 205-236. ISBN 8080682127.

ROTER, D. - HALL, J. 1992. Doctors Talking with Patients/Patients Talking with Doctors. Westport: Auburn House. ISBN 9780275990176. 
SACKS, H. - SCHEGLOFF, E. - JEFFERSON, G. 1974. A Simplest Systematics for the Organization of Turn-Taking for Conversation. In: Language, n. 50, pp. 696-735. ISSN 00978507.

SCHEGLOFF, E. 1984. On Some Questions and Ambiguities in Conversation. In: Atkinson, M. - Heritage, J. (eds.). Structures of Social Action. Studies in Conversational Analysis. Cambridge: Cambridge University Press, pp. 28-52. ISBN 9780521318624.

SEARLE, J. 1975. Indirect Speech Acts. In: Cole, P. - Morgan, JL. (eds.). Syntax and Semantics 3. New York: Academic Press, pp. 59-82. ISBN 9780127854236.

TANNEN, D. 1984. Conversational Style. Analysing Talk among Friends. New Jersey: Ablex. ISBN 9780195221817.

TANNEN, D. 1986. That's Not What I Meant! How Conversational Style Makes or Breaks Your Relations with Others. New York: William Morrow. ISBN 9780345379726.

TARNYIKOVÁ, J. 2000. Pragmatics. In: Štekauer, P. (ed.). Rudiments of English Linguistics. Prešov: Slovacontact, pp. 271-312. ISBN 8088876044.

TODD, A. 1983. A Diagnosis of Doctor-Patient Discourse in the Prescription of Contraception. In Fisher, S. - Todd, A. (eds.). The Social Organization of DoctorPatient Communication. Washington, DC.: The Center for Applied Linguistics, pp. 159-188. ISBN 780155990678.

URBANOVÁ, L. 2003. On Expressing Meaning in English Conversation. Brno: Masarykova univerzita. ISBN 8021032529.

WALLEN, J. - WAITZKIN, H. - STOECKLE, J. 1979. Physicians Stereotypes about Female Health and Illness. In: Women and Health, n. 4, 1979, pp. 135-146. ISSN 03630242 .

WIDDOWSON, H. 1996. Linguistics. Oxford: Oxford University Press. ISBN 9780194372060.

WIERZBICKA, A. 1991. Cross-Cultural Pragmatics. The Semantics of Human Interaction. Berlin: Mouton de Gruyter. ISBN 9783110177695.

YULE, G. 2000. Pragmatics. Oxford: Oxford University Press. ISBN 9780194372077.

\section{Sources}

British National Corpus (XML ed.). Published by Oxford University Computing Services on behalf of the BNC Consortium, 2007.

Words: 9896

Characters: 63116 (35,06 standard pages)

PhDr. Miroslav Černý, Ph.D.

Katedra anglistiky a amerikanistiky

Filozofická fakulta

Ostravská univerzita

70103 Ostrava

miroslav.cerny@osu.cz 